\title{
ICTs, Mindfulness and Emotional Intelligence in Inter-National Educational Policies
}

\author{
$\underline{\text { https://doi.org/10.3991/ijes.v8i4.18543 }}$ \\ Panagiota Anagnostopoulou ${ }^{(凶)}$, Athanasios Drigas \\ Net Media Lab-Mind \& Brain R\&D, \\ N.C.S.R. 'Demokritos', Athens, Greece \\ italgiota@gmail.com
}

\begin{abstract}
The current paper gives a brief description of the position of ICTs, Mindfulness and Emotional Intelligence at the inter-National educational policies. Therefore, many researchers note that ICTs, Mindfulness and Emotional Intelligence play a key role in education for sustainable development and benefit both the teachers and the students. Thus, the research team of this paper presents the contribution of the above practices to the personal and academic growth of the students and also highlights the efforts of the governments to include them in their policies. Lastly, it is worth noting that the inclusion of these practices to the national policies will eventually lead to a sustainable society and should be a priority for the governments.
\end{abstract}

Keywords-ICTs, Mindfulness, Emotional Intelligence, educational policies, sustainable development

\section{$1 \quad$ Introduction}

The Educational Agenda 2030, which was a product of the World Education Forum of 2015, places education as one of the fundamental tools for the sustainable, inclusive, and cohesive development of a country [1]. More specifically, inclusion and equality are seen as the foundation of a holistic vision of education which will contribute to the improvement of the lives of people and societies in general. The Educational Agenda 2030 contains 17 goals for sustainable development (SDGs) to lead the international developmental efforts from 2016 until 2030 and emphasize the need to "leave no one behind" [2]. According to Opertti [1], the Agenda demands the reconsideration of the theory and practices of educational programs.

UNESCO's report of 2018 claimed that ICTs (Information and Communication Technologies) could accelerate the achievement of the SDGs [3]. ICTs concern the study, design, development, application, or management of computer information systems and involve the use of electronic devices and software for the transformation, storage, protection, transmission, and save retrieval of data [4]. According to Buhler and Pelka [5], it is important to include technology to educational programs to ensure that children and adults will develop digital literacy skills [5]. 
Education plays a dual role in sustainable development since it is both the mean and the objective. It can sensitize humans for the problems of the planet and promote the necessary skills to deal with them. However, it is also considered as an aiding process that reveals the abilities and talents of people and helps them in the pursuit of a good life and the improvement of the common good [6].

For the realization of SDGs and the assurance that all humans can be properly educated we need teaching and learning environments that support moral values, like respect, justice, and the absence of violence [6]. For this reason, mindfulness has gained serious attention within the previous couple of years in the search for new pedagogies and innovative processes in educational practice. Mindfulness is "the process of a full, direct, and active realization of phenomena in a psycho-spiritual level that can be maintained from one moment to another" [7].

At the same time, Drigas and Papoutsi [8] claim that if our goal is a better coexistence, but also our personal and social development, we need to emphasize also at the Emotional Intelligence (EI). Only with the development of the EI a person can accept and control his feelings. As a result, EI could offer a much better understanding of the inner world that ends up in better reactions in the outer world [8].

In this project, we will try to present a brief introduction about the role and also the contribution of ICTs, Mindfulness, and Emotional Intelligence in the academic and personal development of the students. Also, we investigate the current educational policies that have already included these elements in their curriculum and we review their results. Finally, we show the significant contribution of ICTs, Mindfulness and EI to the creation of a sustainable society and the actualization of the sustainable development goals.

\section{$2 \quad$ ICTs in International Curricula}

ICTs are considered as a way to promote educational change, improve the capabilities of the students, and prepare them for the world economy and the society of information [9]. The inclusion of modern technology in education has positive effects on the educational development of the countries, their economic progress but also their global position [10]. It is no coincidence that in 2004 the US government had a budget of over 690 million dollars for educational technology. Similarly, Singapore, a country of 4 million people, had a budget of 1 billion dollars during the 5 years of the first information technology program for the installation of computers in schools, school networks, and teacher training [10].

UNESCO had published a toolkit to promote the inclusion of ICTs in the policies of the countries. This toolkit consisted of three levels: wording, programming, and evaluating [11]. Kozma [10], at an article that he published in 2005, presented some general principles that could be helpful for policymakers when they design ICT strategies. These principles include (1) the creation of a clear vision, as the case of Finland where they were supporting that new technology could improve the quality of life, (2) the development of a plan, like the case of Singapore where they created a detailed plan for 
the application of ICTs in education, (3) aligning all the policies and having the ministries follow the same line, and (4) observe and evaluate the results [11].

Policymakers worldwide started the last few years some actions for the promotion of the use of ICTs at their national educational systems. For example, they change the curriculum (Singapore, the Netherlands), they equip the schools with computers and network connections, they create national or even international web pages (European Schoolnet) where the teachers could share their materials and collaborate with their colleagues, they train the teachers in the use of ICTs and they create databases with examples of best practices materials [12].

So, taking into account the importance of technology in the promotion of innovative practices in education, the developed countries, in particular, have suddenly incorporated technology-based strategies into their traditional policies. This trend was not observed by the developing countries until the late 1990s [13]. Since then, the developing countries have adopted revolutionary western policies. The lending policy trend, though, had complicated the application of new technologies to the local African contexts. This was happening because the successful strategies for the developed countries weren't working for the local African communities. Therefore, the specific strategies for the development of ICT skills need to be adapted to the country and its institutional framework [13].

Additionally, the inclusion of ICTs in sub-Saharan Africa had a low priority compared to other objectives, such as increasing the enrollment rate, reducing the number of children leaving school, and ensuring a sufficient number of trained teachers. Hence, in many countries, the introduction of ICTs in education is very slow due to a lack of formal policies, financial recourses, basic infrastructures, and trained teachers. According to the Institute of Statistics of UNESCO (UIS), several African countries don't have an action plan for the application of ICTs in their educational system [3].

Barakabitse et al. [3] mention that the Tanzania Development Vision 2025 emphasized the importance of utilizing ICTs along with the necessary skills and competencies to create a well-educated society and a strong and competitive economy capable of sustainable development. At the same time, in Rwanda, with the vision of the country Vision 2020, they place ICTs at the heart of change in all areas (Smart Rwanda Master Plan, Education Sector Strategic Plan-ESSP, Draft ICT in Education Policy, ICTs in Education Master Plan). The Rwandan government considers ICT to be the key tool for transforming society, with the education sector playing an important role in developing the necessary human resources [3].

The biggest challenge in applying ICTs in education in developing countries is balancing the educational goals and economic reality. The implementation of ICTs requires large capital investments. Due to financial constraints, governments in developing countries are spending most of their education budget for the restoration and maintenance of school buildings and teachers' salaries. In general, the sustainable and effective application of ICT in education requires the provision of adequate infrastructure, access to technologies, and their periodic updating and professional support for teachers [14].

The International Telecommunication Union (ITU) considers that the digital divide that exists between countries is still very large. Poland, for example, has set up distance learning centers to provide education in rural areas. Azerbaijan has developed a national 
strategy to close the digital divide [11]. Egypt established computer clubs for the same purpose. As in other countries, so in Egypt, they target ICTs as a means of economic and social development. However, some obstacles reduce the prospects of success. Illiteracy is at a high level; the current technological infrastructure does not allow widespread use and the participation of the citizens and the freedoms of the press are limited. Technology is very important in the effort of transforming the current state. If Egypt wants to be a part of an information society, then the educational program, the pedagogy, the evaluation, and the use of technology should be aligned with the vision of the future [10].

The last Australian act is the National School Reform Agreement 2019-2023 which emphasizes the development of technical educational programs [15]. In New Zealand, the government had set some goals in 2017 to shorten the digital divide by 2020 . These goals included enhancing social inclusion and cohesion and protecting New Zealanders' digital rights [16].

Iran, with its first attempts of designing programs like Tafka, Roshd Network, and Smart Schools was able to follow the developments. Overcoming challenges such as the weak private sector involvement, lack of long-term financial investment, lack of inservice teacher training, and lack of coherent evaluation strategies can be an important step in developing ICT programs in public education in Iran [15].

In Europe, Finland was the first country which included ICTs within the educational system. With the initiative "ICT in school everyday life 2010", they aimed towards developing the future abilities of the teachers, designed e-learning platforms, and attracted business partners. The European Commission ranks Finland as the most digitalized country in Europe [15].

Agioritis [17] highlighted the importance of the political and economical environment that influences directly the Greek education. More specifically, they argued that the conditions and policies of ICTs in education were unstable due to the economic, political, and social turmoil in which the country had been for years. Also, the infrastructure that was created before the crisis was old-fashioned and was focused on the material instead of training the teachers. Thus, it is urgent that the Greek government alters the political mechanisms and the budget allocation and focus on teacher training and the ways ICTs could be used for promoting an innovative and creative education [17].

At the same time, the European Commission with its e-learning policy aimed at using it as a tool for lifelong learning and strengthening social unity [11]. However, the OECD report of 2015 states that less than $40 \%$ of teachers use ICTs as a means of teaching. The school principals point out that the main obstacles of ICT use are the lack of computers, the limited Internet connection, and the lack of proper software. Teachers consider that being trained in ICTs is the second or even third priority. As reflected in the OECD report (2015), ICTs do not replace traditional tools but complement them [18].

Moreover, it is worth mentioning that the Educational Agenda 2030 speaks about disabled children. The fourth SDG goal is a call on nations to ensure inclusive, qualitative, and fair education and promote lifelong learning opportunities for all [2]. ICTs play a very important role in the inclusion of disabled children in the educational setting and society in general [19]. ICTs for inclusion could be any kind of technology that 
supports learning activities in inclusive environments, including the technology that is commercially available to anyone like laptops, tablets, and mobile phones. However, there are three more types of inclusive technology. Accessible technologies are designed to help students use the main technology without hardships, whereas assistive technologies are aimed at supporting students with disabilities [20]. Finally, there are emerging technologies which are "tools, concepts, innovations, and developments used in different learning environments to serve different learning purposes" [21].

\section{$3 \quad$ Educational Policies and Mindfulness}

Mindfulness is a meditative technique that comes from Buddhist practice [7]. It demonstrates the capability of human consciousness to define the state of "right here and right now", which means the impression of the present moment. It still hasn't appeared in the official educational policy and central study programs. Nevertheless, it appears nowadays on the agenda of the national political discussions for education (OECD, 2017), mainly regarding the social and emotional abilities [22].

Mindfulness is slowly spreading as an innovative technique that supports the learning procedures in various ways. Recently, it caught the attention of the researchers, the professionals, and the policymakers regarding Education for Sustainable Development (ESD) [6].

However, we have to consider why in this world of technology mindfulness is needed. Developing mindfulness techniques, won't make the stress disappear, but will provide the teachers and the students the proper tools to manage this stress. The students can be more focused, productive, and motivated in finishing their assignments and thinking creatively. Also, the learning environment that is created benefits both the teachers and the students, since it gives the necessary space for thinking and reduces impulsive actions and reactions, it promotes critical thinking, and most importantly allows self-evaluation [23].

Therefore, the ecological crisis demands new strategies that will transform our society and make it more sustainable. More and more researches point out the dynamic of mindfulness in altering the motives of people for sustainability [24]. Thierman [24] made a review of the 30 years of researches around mindfulness and sustainability and recognized six main theoretical connections -reduced automation, improved health and well-being, higher connection with nature, improved social skills, recognizing values, and being open to new experiences [24].

Introducing mindfulness in education has passed by several stages. It has been tested in various educational environments, from preschool to adult education targeting both students and teachers. Firstly, it was destined to alter the deviant behavior and improve the educational results of the students [6]. The cultivation of moral values has been recently tested as a possible solution with consequences in sustainability. In our days, mindfulness receives the main acceptance in education [25].

The appearance of international organizations and networks, like the Association for Contemplative Mind in Higher Education (ACMHE 2015), Mind and Life Education Research Network (MLERN 2019), Association for Mindfulness in Education (2019) 
or the British Mindfulness Initiative (2019) proves the influence of mindfulness in today's educational systems [6]. Also, two innovative examples for the inclusion of mindfulness in educational programs are found at Lund University in Sweden and Leuphana Lüneburg University in Germany. The Lund University Centre for Sustainable Studies created in 2015 the Contemplative Sustainable Futures Program. The main objective of the program was to investigate the internal dimensions of mindfulness for sustainability and create learning opportunities for this topic. Leuphana University, on the other hand, is offering classes on sustainability that incorporate two new pedagogical methods that are connected to mindfulness, the reflected production of knowledge, and self-research/ self-experience [6].

According to Laukkonen et al. [26], Mindfulness-based interventions (MBIs), can help students regulate their emotions, become more flexible and creative, and regulate their brain in a way that promotes a higher control of their thoughts, emotions, and actions. These findings prove that mindfulness can also ameliorate the cognitive abilities which are necessary for good learning results and can have a supplementary relation with other kind interventions, like the retrieval practice [26].

In "Mindfulness in Education: The Case of Singapore", Kiat Hui Khng investigates the utilization of mindfulness in the schools of Singapore. He also examines the ways with which mindfulness can be integrated into the educational policy of Asia. According to Khng, the results were positive and included a higher degree of focus, calmness, vigilance, control of the mood, self-knowledge, and stress reduction [27].

People can improve their levels of consciousness mainly by meditating, mental imagery, and self-knowledge in combination with a balanced interaction with the inhibitory and stimulatory networks and the environmental conditions [28]. These kinds of techniques could also help students with ADHD or other neuropsychological disorders to improve their academic results. However, they could be used by anyone seeking personal development, a healthier and happier way of living. After all, personal development and people with self-knowledge could lead to a sustainable society [29].

In Australia, in particular, mindfulness has been a point of dispute in discussions about the future of the national curriculum associated with the growing emphasis on personal and social competence. Furthermore, in the United Kingdom, there was an important review of the consequences of mindfulness in public policy which led to the report Mindful Nation UK. A full chapter of this report is dedicated to education. Globally, many organizations support the introduction of mindfulness in schools, creating a positive climate for it to become part of the general educational practice [30].

McCaw [30] mentions that some applications were developed for the improvement of mindfulness. In Australia, the creators of the application "Smiling Mind" played an important role in defending mindfulness since they made their will to be included in national public policies. Additionally, a few other examples of applications for children are Australian Smiling Mind, Headspace's Meditation for Kids, the Danish Mindfulness for children, and Stop Breathe and Think. These applications provide audiovisual meditations tailored to different ages and school levels [30]. 


\section{The Role of Emotional Intelligence}

Emotions are recognized as one of the fundamental categories of mental functions. The rest are motivation, knowledge, and consciousness [8]. Emotional Intelligence (EI) is the ability to comprehend, use, and regulate emotions. Mainly it connects emotion with knowledge. People with a developed EI can use their emotions to lead their thoughts and behavior and understand the emotions of the others [31].

The first ones who defined emotional intelligence and claimed that some aspects of it can be counted were Salovey and Mayer in 1990 [32]. According to the above researchers, emotional intelligence is "the ability to manage and process emotional information accurately and effectively, including the ability to perceive, assimilate, comprehend and manage the emotions" [33]. It is believed that EI consists of four kinds of abilities: perception, integration, understanding, and management of emotions. Mayer and Salovey described a character with high Emotional Intelligence as a person who can adjust easily, is authentic, persistent, and optimistic.

To present their idea, Salovey and Mayer proposed that emotional intelligence consists of three broad and interrelated abilities: (1) the appreciation and expression of emotion, (2) the regulation of emotion, and (3) the use of emotion to motivate ones' self and others [34].

In the last few years, the interest for Emotional Intelligence is very intense and this is based on the hypothesis that, contrary to IQ, EI could be improved. Also, many of the dangers that humans face, like loneliness, depression, and stress, seem to be connected with emotions. Thus, Neophytou [32] supports that the development of EI could help people acquire a higher interest for our planet and violence could be replaced with empathy.

An important element of understanding EI is the knowledge of what causes our emotions. In what is known as the "Amygdala Hijack", the people feel before they think, our emotional side is activated first or at the same time with the rational side of our brain. The centers of emotions are found lower in the brain, in the most ancient subcortex. Emotional Intelligence requires that these centers are activated. By understanding what causes our emotions we can avoid emotional violation and behave more rationally [35].

Emotional intelligence is now discussed as an educational policy issue because for some researchers it is considered as important, and sometimes more important, than IQ in predicting success in life. So, researchers are beginning to wonder if schools should design policies directed at improving EI [33].

According to Mayer and Cobb [33], the connection of EI with education came from Goleman, who extended EI with a list of personal characteristics like optimism, adjustment, and motive. He believed that EI represents the "character". Therefore, this "character" could be improved in school settings. He thought that by monitoring students' emotional abilities would lead to a community where people care for each other and the students feel respected and connected to their classmates. The specialists of educational policy quickly accepted the idea that EI as a predictor of success.

Emotional Intelligence can be integrated with various ways in politics and existing curricula. For example, it could be enhanced by art programs. Also, the discussion about 
the feelings of the characters in a story or what kind of emotions a piece of music evokes may encourage emotional perception and understanding. For the students, in particular, EI could help them manage emotions like stress and depression, increase their selfesteem, and feel satisfied with their work as they use strategies to control their emotions [36]. Emotional intelligence also plays an important role in students' academic performance, as well as in their social and mental well-being [36].

Children who understand and regulate emotions and who are more emotionally positive when entering school are more likely to develop positive and supportive relationships with peers and teachers, participate more and achieve higher levels throughout the first years of school. On the contrary, children who go to school with fewer emotional skills are more likely to be rejected by their peers, develop less supportive relationships with their teachers, participate and enjoy school less, and are at risk for later school difficulties [37].

At the same time, Sherlock [35] argues that EI could be integrated also at the International curriculum to develop more easily the values of inclusion, respect, and tolerance which are promoted in these schools. The model that was developed in the article of Sherlock consists of three pillars that could help the development of emotional intelligence. The first is self-understanding, which begins with self-awareness and ends with the development of self-control. The second is the understanding of the others, which means developing empathy, active listening, and appreciation for inclusion and diversity. Finally, the third pillar is technical and it includes knowledge [35].

Education is one of the biggest applied sectors of EI. The emphasis in Social and Emotional Learning (SEL) is growing rapidly at all levels of the education system, from pre-school to secondary education and from school to vocational programs [34].

Nowadays, SEL is internationally recognized in hundreds of classroom programs integrated into a common framework. Collaborative for Academic, Social, and Emotional Learning (CASEL) is a reliable source of knowledge about social and emotional learning (SEL). CASEL supports educators and policy leaders and improves experiences and outcomes for all students [34]. A meta-analysis of more than 200 randomized controlled trials of school-based universal SEL programs supported the effectiveness of enhancing students' social-emotional skills and improving their behavioral, social, and academic skills as well as their well-being [38]. Also, they had increased levels of academic achievement, relationship quality, emotional skills, and less problematic behaviors [38, 39].

By definition, SEL programs integrate the teaching of emotional skills, such as recognizing, highlighting, and regulating emotions, into the traditional curriculum of reading, writing, and arithmetic. Helping students be responsible and self-regulated, SEL programs also play a role in supporting children's school readiness and academic achievement [39].

Hoffman, Ivcevic, and Brackett [39] presented the RULER approach to SEL programs. RULER aims to form emotionally intelligent schools and communities. RULER stands for "Recognizing, Understanding, Labeling, Expressing and Regulating emotions" [39]. This approach emphasizes the power of labeling emotions that refers to creating connections between emotional experience and emotional words. Students and teachers ought to develop their emotional lexicon. The more emotional words an 
individual is aware of, the more accurately they can express their feelings, communicate how they feel to others, and perceive how others feel. Students who can accurately point out emotions have more positive social interactions and perform better in school, whereas students who struggle to point out emotions have more behavioral and learning difficulties [39].

Emotional processes vary significantly as a result of cultural differences. These variations, however, have been largely neglected within the study of EI. Scholars should integrate intercultural issues into EI models, and researchers ought to acknowledge the cultural context in which their work is located and avoid generalizations beyond the cultural boundaries of their results [40].

\section{Conclusion}

In conclusion, ICTs are now found at the heart of human development as they are responsible for the economic and social development of recent decades. All the skills and knowledge needed from the students of our century have been revaluated since it is now well known that the knowledge-based economy is linked to ICTs. Additionally, researchers agree that mindfulness is a way to experience higher levels of consciousness and be led to the highest form of self-knowledge. Accordingly, the development of emotional intelligence could lead to a community in which mutual respect prevails. After the review, we observe that the governments and the international organizations have realized the value of ICTs, Mindfulness, and EI. They have already started incorporating ICTs into their educational policies, writing reviews that promote Mindfulness in Education and include SEL programs in the school's curricula. Finally, the inclusion of the above practices into educational policies could lead to a sustainable society and benefits the students both at the academic and at the personal level.

\section{$6 \quad$ References}

[1] R. Opertti, "Curriculum in the Education 2030 Agenda: Latin America and the Caribbean; Current and critical issues in curriculum, learning and assessment," UNESDOC Digital Library Current and Critical Issues in Curriculum, Learning and Assessment, no. 10, May 2017. Available: https://unesdoc.unesco.org/ark:/48223/pf0000248238. [Accessed: January 28, 2020].

[2] S. Mizunoya, S. Mitra, and I. Yamasaki, "Towards Inclusive Education: The Impact of Disability on School Attendance in Developing Countries," Innocenti Working Paper, no. 201603, May 2016. Available: https://papers.ssrn.com/sol3/papers.cfm?abstract_ $\mathrm{id}=2782430$. [Accessed: January 28, 2020]. https://doi.org/10.18356/36cadbae-en

[3] A.A. Barakabitze, A. William-Andey Lazaro, N. Ainea, M. H. Mkwizu, H. Maziku, A.X. Matofali, A. Iddi, and C. Sanga, "Transforming African Education Systems in Science, Technology, Engineering, and Mathematics (STEM) Using ICTs: Challenges and Opportunities," Education Research International, vol. 2019, February 2019. Available: https://doi.org/10.1155/2019/6946809. [Accessed: June 20, 2020]. 
[4] M. A. Shuja, "Connecting people with disabilities: ICT opportunities for all," Munich Personal RePEc Archive, September 2009. Available: http://mpra.ub.uni-muenchen.de/17204/. [Accessed: January 28, 2020].

[5] C. Buhler and B. Pelka, "Technology for Inclusion and Participation Introduction to the Special Thematic Session. Computers Helping People with Special Needs," ICCHP, 13th15th July 2016, pp. 76-79. Available: https://link.springer.com/content/pdf/bfm\%3A978-3319-41264-1\%2F2\%2F1.pdf. [Accessed: January 28, 2020].

[6] P. Frank, D. Fischer, and C. Wamsler, "Mindfulness, Education, and the Sustainable Development Goals," in Encyclopedia of the UN Sustainable Development Goals. Quality Education, vol. 10. W. Leal Filho, A. M. Azul, L. Brandli, P. G. Özuyar, \& T. Wall Eds. Cham: Springer, 2019, pp. 1-11. Accessed on June 21, 2020 [Online]. Availble:https://www.researchgate.net/publication/336684001_Mindfulness_Education_and_the _Sustainable_Development_Goals. https://doi.org/10.1007/978-3-319-69902-8_105-1

[7] W. Van Gordon, S. Sapthiang, E. Shonin, and M. D. Griffiths, "Mindfulness for Addressing Key Public Health Concerns in Young People: Preventative Applications and Safety Concerns," Education and Health, vol. 37, no. 1, pp. 9-14, May 2019. Available: https://derby.openrepository.com/handle/10545/623725. [Accessed: June 20, 2020].

[8] A. Drigas and C. Papoutsi, "A new layered model on emotional intelligence," Behavioral Sciences, vol. 8, no. 5, May 2018. Available: https://doi.org/10.3390/bs8050045. [Accessed: January 28, 2020].

[9] M. Njoki and F. Wabwoba, "The Role of ICT in Social Inclusion: A Review of Literature," International Journal of Science and Research (IJSR), vol. 4, no. 12, pp. 380-387, January 2015. Available: https://doi.org/10.21275/v4i12.nov151897. [Accessed: January 27, 2020].

[10] R. B. Kozma, "National Policies that Connect ICT-Based Education Reform to Economic and Social Development," Human Technology. An Interdiscipline Journal on Humans in ICT Environments, vol. 1, no. 2, pp. 117-156, October 2005. Available: https://humantechnology.jyu.fi/archive/vol-1/issue-2/kozma1_117-156 [Accessed: February 3, 2020]. https://doi.org/10.17011/ht/urn.2005355

[11] L. Mohebi, "“'Towards a General Framework for ICT and e-Learning Educational Policy in the United Arab Emirates," SSRN Electronic Journal, August 2019. Available: https://doi.org/10.2139/ssrn.3441563. [Accessed: June 20, 2020].

[12] T. Plomp, W. J. Pelgrum, and N. Law, "SITES2006-international comparative survey of pedagogical practices and ICT in education," Education and Information Technologies, vol. 12, no. 2, pp. 83-92, June 2007.Available: https://link.springer.com/article/ 10.1007/s10639-007-9029-5. [Accessed: January 28, 2020]. https://doi.org/10.1007/ $\underline{\mathrm{s} 10639-007-9029-5}$

[13] D. Petronzi and M. Hadi, "Exploring the Factors Associated with Mooc Engagement," European Journal of Open, Distance and E-Learning, vol. 19, no. 2, pp. 129-146, December 2016. Available: https://eric.ed.gov/?id=EJ1138117. [Accessed: June 20, 2020]. https://doi.org/10.1515/eurodl-2016-0011

[14] S. Salam, J. Zeng, Z. H. Pathan, Z. Latif, and A. Shaheen, "Impediments to the integration of ICT in public schools of contemporary societies: A review of literature," Journal of Information Processing Systems., vol. 14, no. 1, pp. 252-269, January 2018. Available: http://jips-k.org/q.jips?cp=pp\&pn=541. [Accessed: June 20, 2020].

[15] M. Kian, "A Comparative Study of ICT Programs in Basic Education in Australia, Finland and Iran, " Iranian Journal of Comparative Education, vol. 2, no. 3, pp. 383-406, February 2020. Available: http://journal.cesir.ir/article_103834.html. [Accessed: June28, 2020].

[16] C. Cotter, "ICTs as an Antidote to Hardship and Inequality implications for New Zealand," Policy Quarterly, vol. 14, no. 2, pp. 80-87, May 2018. Available: 
https://www.victoria.ac.nz/_data/assets/pdf_file/0011/1500869/PQ14-2-Cotter.pdf. [Accessed: June 20, 2020]. https://doi.org/10.26686/pq.v14i2.5098

[17] G. Agiorgitis, "ICTs use in the public Greek Primary Schools: the teachers' experiences," M.S. thesis, Department of technology, Linaeous University, Sweden, 2017. Accessed on: June, 17, 2020 [online]. Available: https://www.diva-portal.org/smash/get/diva2:1156 272/FULLTEXT01.pdf.

[18] M. Area-Moreira, V. Hernández-Rivero, and J. J. Sosa-Alonso, "Models of educational integration of ICTs in the classroom," Comunicar Media Education Research Journal, vol. 24, no. 47, pp. 79-87, March 2016. Available: https://www.scipedia.com/public/AreaMoreira et al 2016a. [Accessed: February 3, 2020]. https://doi.org/10.3916/c47-2016-08

[19] A. Drigas and R.E. Ioannidou, "ICTs in Special Education: A Review" in Information Systems, E-learning, and Knowledge Management Research. WSKS 2011. Communications in Computer and Information Science, M.D. Lytras., D. Ruan, R.D Tennyson, P. Ordonez De Pablos., F.J García Peñalvo, and L. Rusu Eds. Berlin: Springer, vol. 278. Accessed on: January 28, 2020 [Online]. Available: http://imm.demokritos.gr/publications/ ICTs\%20in\%20Special\%20Education_A_Review.pdf. https://doi.org/10.1007/978-3-64235879-1

[20] G. Alnahdi, V. Dean, and S. Arabia, "Assistive Technology in Special Education and the Universal Design for Learning," Turkish Online Journal of Educational Technology, vol. 13, no. 2, pp. 18-23, January 2014. Available: http://www.tojet.net/articles/v13i2/1322.pdf. [Accessed: January 27, 2020].

[21] C. T. M. Cao, "Information and Communication Technologies in Inclusive Education: Selected Practices in Asia," Journal of education and learning, vol. 8, no. 6, p. 159, November 2019. Available: http://www.ccsenet.org/journal/index.php/jel/article/view/0/41184. [Accessed: January 28,2020$]$.

[22] OECD. (2017). Bridging the Gap: Inclusive Growth 2017 Update Report. Available: http://www.oecd.org/inclusive-growth/Bridging_the_Gap.pdf\%0D. [Accessed: January 28, 2020].

[23] E. D. Elia, “The Balancing Act: Using Mindfulness in a Technology Driven World," New Jersey English Journal, vol. 9, no. 3, April 2020. Available: https://digitalcommons.montclair.edu/nj-english-journal/vol9/iss1/3. [Accessed June 28, 2020].

[24] U. B. Thiermann and W. R. Sheate, "The Way Forward in Mindfulness and Sustainability: a Critical Review and Research Agenda," Journal of Cognitive Enhancement, July 2020. Available: https://doi.org/10.1007/s41465-020-00180-6. [Accessed: July 23, 2020].

[25] P.D Zelazo and K.E. Lyons, "The Potential Benefits of Mindfulness Training in Early Childhood: A Developmental Social Cognitive Neuroscience Perspective," Child Development Perspectives, vol. 6, no.2, pp. 154-160, June 2012. Available: https://doi.org/10. 1111/j.1750-8606.2012.00241.x. [Accessed: January 27, 2020].

[26] R. E. Laukkonen, J.M. Leggett, R.M. Gallagher, H.L. Biddell, A.J. Mrazek, H.A. Slagter, and M.D. Mrazek, "Future of Education and Skills 2030: Curriculum Analysis the Science of Mindfulness-Based Interventions and Learning: A Review for Educators in EDU/EDPC (2019)15/REV1, OECD 10th Informal Working group, Ilsan and Seoul, Korea, October 2325, 2020. Accessed on June 28, 2020. [Online]. Available: https://www. oecd.org/education/2030-project/contact/The_Science_of_Mindfulness-Based_Interven tions_and_Learning_A_Review_for_Educators.pdf. https://doi.org/10.31231/osf.io/6g9uq

[27] K. Tobin, "Mindfulness in education," Learning: Research and Practice, vol. 4, no. 1, pp. 1-9, March 2018. Available: https://doi.org/10.1080/23735082.2018.1433623. [Accessed: June 21, 2020]. A Kao, and S.R. Poteet, Eds., Natural Language Processing and Text mining. London: Springer Publishing Company, 2007. 
[28] A. Drigas and E. Mitsea, "The Triangle of Spiritual Intelligence, Metacognition and Consciousness," International Journal of Recent Contributions from Engineering, Science \& IT (IJES), vol. 8, no.1, pp. 4-23, March 2020. Available: https://doi.org/10.3991/ ijes.v8i1.12503. [Accessed: January 28, 2020].

[29] A. Drigas and M. Karyotaki, “A Layered Model of Human Consciousness," International Journal of Recent Contributions from Engineering, Science \& IT (IJES), vol. 7, no. 3, pp. 41-50, September 2019. Available: https://doi.org/10.3991/ijes.v7i3.11117. [Accessed: January 28,2020$]$.

[30] C.T. McCaw, "Mindfulness 'thick' and 'thin' - a critical review of the uses of mindfulness in education," Oxford Review of Education, vol. 46, no. 2, pp. 257-278, October 2019. Available: https://doi.org/10.1080/03054985.2019.1667759. [Accessed: June 28, 2020].

[31] O. Serrat, "Understanding and Developing Emotional Intelligence" In Knowledge Solutions. Singapore: Springer, 2017, pp. 329-339. Accessed on: January 28, 2020 [Online]. Available: https://link.springer.com/chapter/10.1007/978-981-10-0983-9_37. https://doi.org/10.1007/ 978-981-10-0983-9_37

[32] L. Neophytou, "Emotional intelligence and educational reform," Educational Review, vol. 65, no. 2, pp. 140-154, January 2012. Available: https://doi.org/10.1080/00131911.2011. 648171. [Accessed: February 3, 2020].

[33] J.D. Mayer and C.D. Cobb, "Educational Policy on Emotional Intelligence: Does it make sense?" Educational Psychology Review, vol. 12, no. 2, pp. 163-183, October 2000. Available: https://link.springer.com/article/10.1023/A:1009093231445. [Accessed: January 28, 2020].

[34] K. V Keefer, J.D.A. Parker \& H. Saklofske, "Three Decades of Emotional Intelligence Research: Perennial Issues, Emerging Trends and Lessons Learned in Education: Introduction to Emotional Intelligence in Education", in Emotional Intelligence in Education Integrating Research with Practice, K. V Keefer, J.D.A. Parker \& H. Saklofske Eds. Switzerland: Springer International Publishing AG, 2018, ch.1, pp. 1-19. Accessed on: July 28, 2020. [Online]. Available: https://link.springer.com/book/10.1007\%2F978-3-319-90633-1. https://doi.org/10.1007/978-3-319-90633-1_1

[35] P. Sherlock, "Emotional Intelligence in the International Curriculum," Journal of Research in International Education, vol. 1, no. 2, pp. 139-158, December 2002. Available: https://doi.org/10.1177/147524002764248112. [Accessed: January 27, 2020].

[36] P. Puertas-Molero, F. Zurita-Ortega, R. Chacón-Cuberos, M. Castro-Sánchez, I. RamírezGranizo, and G. González-Valero, "Emotional intelligence in the field of education: A metaanalysis," Anales de Psicologia, vol. 36, no.1, pp. 84-91, January 2020. Available: https://doi.org/10.6018/analesps.345901. [Accessible: June 28, 2020]. https://doi.org/10. 6018/analesps.345901

[37] S. A. Denham \& H.H. Bassett "Implications of preschoolers' emotional competence in the classroom", in Emotional Intelligence in Education Integrating Research with Practice, $\mathrm{K}$. V Keefer, J.D.A. Parker \& H. Saklofske Eds. Switzerland: Springer International Publishing AG, 2018, ch.6, pp. 135-171. Accessed on: July 28, 2020. [Online]. Available: https://link.springer.com/book/10.1007\%2F978-3-319-90633-1. https://doi.org/10.1007/ 978-3-319-90633-1_6

[38] K. V Petrides, M.J. Sanchez-Ruiz, A.B. Siegling, D.H. Saklofske \& S. Mavroveli "Emotional Intelligence as a Personality: Measurement and Role of Trait Emotional Intelligence in Educational Contexts", in Emotional Intelligence in Education Integrating Research with Practice, K. V Keefer, J.D.A. Parker \& H. Saklofske Eds. Switzerland: Springer International Publishing AG, 2018, ch.3, pp. 49-81. Accessed on: July 28, 2020. [Online]. 
Available: https://link.springer.com/book/10.1007\%2F978-3-319-90633-1. https://doi.org/ 10.1007/978-3-319-90633-1 3

[39] J.D. Hoffmann, Z. Ivcevic \& M.A. Brackett "Building emotionally intelligent schools: from preschool to high school and beyond", in Emotional Intelligence in Education Integrating Research with Practice, K. V Keefer, J.D.A. Parker \& H. Saklofske Eds. Switzerland: Springer International Publishing AG, 2018, ch.7, pp. 173-198. Accessed on: July 28, 2020. [Online]. Available: https://link.springer.com/book/10.1007\%2F978-3-319-90633-1. https://doi.org/10.1007/978-3-319-90633-1_7

[40] A.C. Huynh, H. Oakes \& I. Grossmann "The role of culture in understanding and evaluating emotional intelligence", in Emotional Intelligence in Education Integrating Research with Practice, K. V Keefer, J.D.A. Parker \& H. Saklofske Eds. Switzerland: Springer International Publishing AG, 2018, ch.5, pp. 111-132. Accessed on: July 28, 2020. [Online]. Available: https://link.springer.com/book/10.1007\%2F978-3-319-90633-1. https://doi.org/ 10.1007/978-3-319-90633-1_5

\section{Authors}

Panagiota Anagnostopoulou is a research associate at N.C.S.R. "Demokritos", IITNet Media Lab \& Mind - Brain R\&D, Agia Paraskevi, 153 10, Athens, Greece (email: italgiota@gmail.com).

Athanasios Drigas is a Research Director at N.C.S.R. "Demokritos", IIT - Net Media Lab \& Mind- Brain R\&D, Agia Paraskevi, 153 10, Athens, Greece (e-mail: dr@iit.demokritos.gr).

Article submitted 2020-09-14. Resubmitted 2020-10-14. Final acceptance 2020-10-14. Final version published as submitted by the authors. 